\title{
Management Information Systems - The Impact of 5G Technologies: A Case of Africa
}

\author{
Josephine Shailemo \\ Department of Management, Texila American University, Namibia
}

\begin{abstract}
The study embarked on the management of information systems, what it is all about as well as the impact of fifth generation $(5 G)$ technologies, the advantages and disadvantages, and the countries that roll out $5 G$ technologies in Africa. The study was done in some African countries, specifically South Africa, Lesotho, Namibia, and Nigeria. The study employed a survey research design and used a case study approach. Primary data were collected from the mentioned countries. Respondents were companies and few randomly identified individuals. The study identifies the advantages as well as disadvantages of $5 G$ technologies. The study results show that most African countries are still to invest in $5 G$ technologies and those that are using them are yet to bear heavy costs.
\end{abstract}

Keywords: Africa, Management Information Systems, 5G, Technologies.

\section{Introduction}

The advancement of technology placed a major role on how the information should be treated, shared, captured, and/or saved, especially in this changing environment. Management of information systems (MIS) is a computerized database of factual information arranged in a way that gives clear and concise meaning on how things should be done. Some information, such as reports, could easily be retrieved from the system (Encyclopedia). Special reports could easily be obtained from the system [1].

A management information system (MIS) is used for decision-making, planning, organising, commanding, supervising, and imagining information [2].

The study of management information involves people, processes, and technology in an organizational context [2]. Management information systems in an organization can be defined as a way of gathering adequate information in a prescribed format. It is a system designed to provide selected decision orientation information needed by the management scheme, supervise, and assess all the undertaking and projects of the organization. It is designed within the framework that emphasis surplus, arrangement of performance in a systematic way at all tiers of the organization [3]. It complements the ultimate integration of required business information subsystem financial within the company. An information system is a series and sequence of information ranging from human beings, computers, and other operating systems of a firm.

The fifth generation (5G) is the next generation of mobile internet technology and comes on the heels of the fourth generation's long-term evolution (4G LTE) standard. The fifth generation $(5 \mathrm{G})$ promises radically faster download and upload times. Websites will open in microseconds, and videos will download in seconds rather than in minutes. Sometimes $5 \mathrm{G}$ could be very disruptive as it can cause reverberation sounds on cellular phones, especially with some phone settings. Also, 5G causes some changes in the way humans live and shorten the speed and rate upon sending and delivering of information, and it is instant 
from the human perspective, said Muyiwa Matuluko, editor-in-chief of TechPoint Africa, a tech-focused platform based in Nigeria. The fifth generation (5G) is a sudden change, following the other group of Telecom networks that was discovered in the market end of 2018 and is still spreading globally. Apart from upgrading speed, the huge release of $5 \mathrm{G}$ IoT (Internet of Things) ecosystem, whereby greater numbers of devices will be linked together to save cost and time $[4,5]$.

The key functional drives of $5 \mathrm{G}$ will unlock a broad range of opportunities, including optimizing of service delivery, decisionmaking, and end-user experience (Hazem Galal - Global leader, Cities \& Local Government, PWC, Middle East). According to Hazem Galal, 5G will be critical because it will enable unprecedent levels of connectivity, upgrading $4 \mathrm{G}$ networks with five key functional drivers: supper fast broadband, ultra-reliable low latency communication, massive machine-type communications, high reliability/availability, and efficient energy usage [6].

\section{Aims and Objectives of the Study}

Aim

To understand the connection between the term management of information systems and $5 \mathrm{G}$ technologies.

\section{Objectives}

To understand the meaning of management of information systems and the $5 \mathrm{G}$ technologies.

To determine the advantages as well as the disadvantages of $5 \mathrm{G}$ technologies.

To make a recommendation on the merits and demerits of $5 \mathrm{G}$ technologies.

\section{Statement of the Problem}

Management of Information systems is not an easy task nor a way in a park but rather a radical obligation to handle massive information.
It is important that the right information gets to the right person at a reasonable time. If wrong information gets to the wrong person, it creates and brings confusion. Hence the process of management of information system should be guided responsibly. Many countries throughout the world have been in a good cause in managing information systems like India is one in the world, South Africa, and Egypt in Africa [7].

To keep up with the pace of time, the birth of $5 \mathrm{G}$ has entered the world and then spread to the Africa continent. In Africa, Lesotho, South Africa, and Nigeria, 5G copyright items are read available to buy, and the services are quite extremely limited. In some countries like Lesotho, 5G is limited to some companies [8].

At this pace of time when technology is taking over the majority of African countries would not want to be left behind with technology, but the point is will they afford $5 \mathrm{G}$ ? Do they consider the negative impact that $5 \mathrm{G}$ imposes on people and the community at large, and are they ready for 5G? Some of the Africans are happy with the advent of 5G, but the majority are still in fear as $5 \mathrm{G}$ imposes danger and health hazards to living organisms. [9], in their article: We have no reason to believe $5 \mathrm{~g}$ is safe, they have stated that numerous recent scientific publications have shown that EMF (electromagnetic field) affects living organisms at levels well below most international and national guidelines. They further indicated that will cause some serious health hazards and will have a negative impact on living organisms to both flora and fauna.

\section{Literature Review}

\section{Advantages and Disadvantages of 5G}

The fifth-generation technology offers a variety of features, which are beneficial for all groups of people including, students, professionals (doctors, engineers, teachers, governing bodies, administrative bodies etc [10]. 


\section{Important Advantages (Merits)}

According to Dilsha and Neenu, some numerous favourable of $5 \mathrm{G}$ technology are:

1.High resolution and bi-directional large bandwidth shaping.

2. The application of scientific knowledge to collect networks in one space.

3. More effective and efficient.

4.Technology to help subscriber administration tools for faster response.

5.Again, it will yield the gigantic broadcasting of data and support more connectivity.

6. Easily manageable with the previous generations.

7.Technology helps to similar network services (including private networks).

8. Viable to supply, same, continuous, and similar connection over the globe.

9. Resemble various services that you can choose from while talking on the phone to another person.

10. You can control your personal computers (PCs) by handsets.

11. Teaching will be unchallenging; a learner will attend virtual lessons wherever they are in the world. 5G could enable live streaming in a virtual reality classroom. One can imagine students being able to sit wherever they are and take classes, "says Matuluko".

12. Medical treatment will become easier and economical, and medical practitioners can give medical care or attention to a patient at a different place.

13. Observation will be simple and unchallenging government entities can monitor any section of the world to minimize misdemeanor.

14. Imagining cosmos, the milky-way, plants, and other spacecraft will be achieved.

15. Practicable to locate and look for a lost human being.

16. Possible natural disasters, including tsunamis, earthquakes etc., can be detected faster.
Disadvantages (Demerits) of $5 G$ Technology

Although 5G technology is supposed to answer all problems related to telecommunications but for some safety issues and insufficient modern technology in geographical areas. It has these failures:

1. Technology is still under process, and research on its viability is going on.

2. The rate of technology seems hard to reach (in the future, it might be) due to inept and clumsy technological aid in many corners of the globe.

3. The majority of the outdated devices would not be an expensive deal.

4. High cost in developing infrastructure.

5. The safeguarding of user identity and privacy matters will be sorted out.

\section{The Impact of $5 \mathrm{G}$ on the African Countries - Namibia in General}

The country will embark on evaluating of the environment to determine the effect of $5 \mathrm{G}$ before rolling it out. The ministry of environment, forestry and tourism had a responsibility of conducting a review just few days ago before the municipality of Windhoek disclose and uplift the mobile network of the city, so that it prepares and ready for $5 \mathrm{G}$. Telegeography records that the town already accepted excellent, first-rate electronic communication network services and electronic communications facility licenses from regulator CRAN (Communications Regulatory Authority of Namibia) early March 2020. The environmental evaluation, which was made public, which the government considered by instructing CRAN to submit a $5 \mathrm{G}$ plan for the country and present it to the cabinet. Peya Mushelenga, the minister of information, indicated that before the introduction of $5 \mathrm{G}$, it is advisable to assess the environment. [11]. 


\section{Conceptual Framework of 5G}

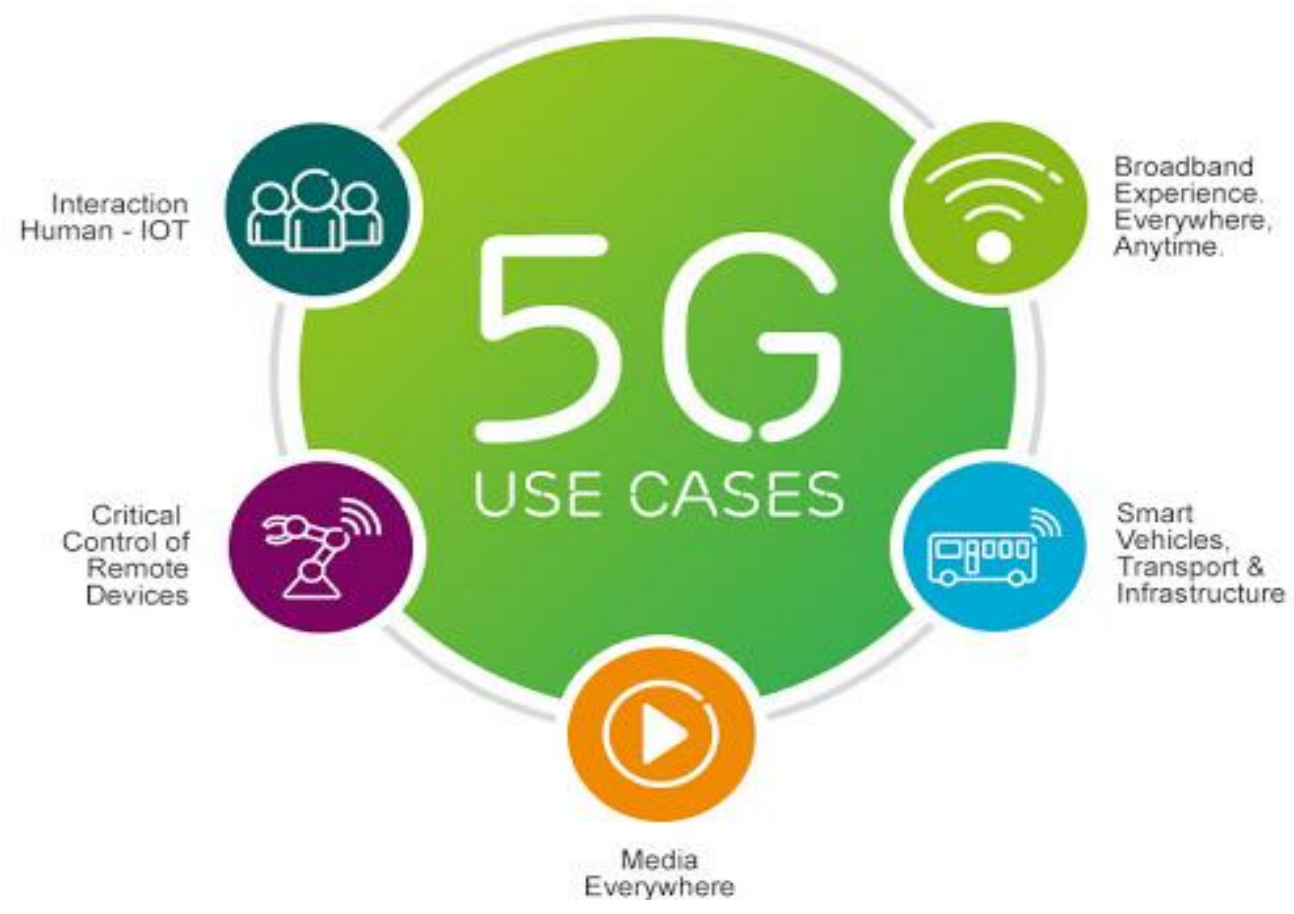

Figure 1. Usage of $5 \mathrm{G}$

The Diagram Illustrate the Various Services Offered by 5G Technologies

$5 \mathrm{G}$ offers several opportunities ranging from media, smart vehicles, transport and infrastructure, critical control of remote devices, interaction human - IoT (Internet of Things), and broadband experience everywhere, anytime.

\section{Materials and Methods}

\section{Type of Study}

A mixed approach kind of study was employed of which primary data were collected from individuals and companies as well as secondary data generated from the internet, journals, articles, blogs, and books. The study used a case study approach because it enables researcher (s) to conduct an in-depth exploration of intricate phenomenon within some specific context [12].

A case study method is regarded as the greatest and extensively used method in academia for the researcher(s) interested in qualitative research [13]. By including both qualitative and quantitative data, case study assists in expressing all the processes and outcomes of a phenomenon through complete observation, reconstruction, and analysis of the case under investigation [14]. [15] in their research titled: Case study as a research method, they define case study as a method that enables a researcher to closely examine the data within a specific context, whereby in most cases, a case study way that helps a researcher to involves the study of data within a specific circumstance in most situation, a case study method chooses a tiny geographical region or a very restricted number of individuals as the subjects of study. They further added that case studies naturally explore and investigate contemporary real-life situations under a complete contextual scanning of a fewer numbers of events or circumstances, and their connections.

\section{Population and Sample}

The study population is taken from the four countries, Lesotho, Namibia, Nigeria, and South Africa, of which a total sample of 150 people/respondents were drawn from. 


\section{Data Collection}

Data were collected only in the four countries (Lesotho, Namibia, Nigeria, and South Africa) in Africa from December 2020 to mid-January 2021. Interview was one of the major data collection techniques. Some questionnaires were mailed to few companies that have access to the internet and could easily respond to the researcher on time.

\section{Data Analysis Procedure}

Data were presented, analyzed, and interpreted in bullets sentences, straight paragraphs, and figures.

\section{Results and Discussion}

All data collected are presented as follows:

\section{Advantages and Disadvantages of 5G}

The $5^{\text {th }}$ generation technology brought many changes to benefits groups of people, including students, professionals (doctors, engineers, teachers, governing bodies, administrative bodies, and many more. Some of the advantages/merits of $5 \mathrm{~g}$ are listed below:

1. High resolution and bi-directional large bandwidth shaping.

2. Technology to collect all networks on one platform.

3. More effective and efficient.

4. Technology to ease subscriber supervision tools for a faster response.

5. Probably, it will yield massive broadcasting data (in Gigabit), which will assist over 60,000 connections.

6. Easily manageable with the previous generations.

7. Technological sound to assist diverse services (including private networks).

8. Possible to provide the same, continuous, and consistent connectivity over the globe.

9. Resemble various services, such as locating another caller while on the phone with a different person.

10. You can control your personal PCs by handsets.
Teaching will become unchallenging, a learner from another corner of the globe can attend the lesson. 5G could enable live streaming in a virtual reality classroom.

1. Medical treatment will become easier and economical, and a medical practitioner can give medical care or attend to the patient located at a different place.

2. Observation will be simple and unchallenging, government entities and investigating can monitor any section of the world to minimize misdemeanor.

3. Imagining cosmos, the milky-ways, planets, and space crafts will be achieved.

4. Practicable to locate and look for people who are lost.

5. Possible natural disasters, including tsunamis, earthquakes etc., can be detected faster.

6. Since this study is about the impact of 5G technology here, are some disadvantages that come along with $5 \mathrm{G}$.

Although 5G technology is researched and conceptualized to solve all radio signal problems and hardships of the mobile world, because of some security reasons and lack of technological advancement in most of the geographic regions, it has the following shortcomings:

1. The rate of technology seems hard to reach (years to come, it might be) due to inept and clumsy technological aid in many corners of the globe.

2. The majority of the outdated devices would not be an expensive deal.

3. High cost in developing infrastructure.

4. The safeguarding of user identity and privacy matters will be sorted out.

\section{Conclusion, Recommendations, and Limitations}

\section{Conclusion}

As per the findings of the study, it can be concluded that Africans are quite happy about the advent of $5 \mathrm{G}$, although it is costly to implement and install, but yes, countries are 
trying to invest in 5G technology as they do not want to be left behind. The $5 \mathrm{G}$ technologies help to speed up the business process, it helps to ease and aid the communications process, but $5 \mathrm{G}$ also has some demerits to both living and non-living organisms.

\section{Recommendations}

African countries should be on alert when it comes to the usage of $5 \mathrm{G}$ technologies. It is not a bad idea to introduce it and the concern is the cost and problems it causes. It is advisable for countries to conduct a pre-and postenvironmental assessment to assess the environmental impact of $5 \mathrm{G}$ before introducing it to the market as well as after the invention, as those who carry the same research are saying that it is risky to implement $5 \mathrm{G}$ technologies.

\section{Limitations}

The study is about the entire Africa continent but, it was limited to four countries only as it was not possible for the researcher to include all countries in Africa. Time and resources were some major limitations that hinder the study from being conducted in all African countries. The study was conducted during the period of second wave of Coronavirus, as per World

\section{References}

[1]. Encyclopedia, 2021: Special Reports could easily be obtained from the system; Management Information Systems (MIS) retrieved from: https://www.inc.com/encyclopedia/managementinformation-systems-mis.html.

[2]. The Free Encyclopedia, 2021, Managementinformation-system retrieved from: https://en.wikipedia.org/wiki/managementinformation-system.

[3]. Adikesavan, T. (2014). Management Information Systems: Best Practices and Applications in Business. PHI Learning Private Limited, $2^{\text {nd }}$ Edition. https://www.amazon.com.
Health Organization protocol and procedure for coronavirus lockdown, it was not possible for the researcher to travel freely to conduct research.

\section{Acknowledgements}

Giving honour and glory to God our saviour for allowing and granting me life to complete this article. I am deeply pleasurable to thank people who have supported me. My deepest gratitude goes to Mr. Surya Prabhu, for mentoring me throughout, Sir, your words of encouragement and support is endless.

To the (respondents) from Lesotho, Namibia, South Africa, and Nigeria who participated in the study, I am indebted. To my Texilian family, you are awesome.

Lastly, my family, my pillar of strength, your unwavering support is appreciated. Death has stilled the voice of my brother Joseph Kondjeni, but it will never mute his encouragement which still nourishes me. I salute you all.

\section{Conflict of Interest}

The author has no conflict of interest.

[4]. What is 5G? retrieved from: https://www.thalesgroup.com/en/markets/digitalidentity-and-security/mobile/inspired/5G.

[5]. 5G technology and networks (speed, use cases, rollout)-Thales retrieved from https://www.thalesgroup.com.

[6]. The Impact of 5G: Creating New Value across retrieved from https:// www.pwc.com/.

[7]. Master Information Systems Management retrieved from: https://www.bestmasters.com/ranking-master-information-systemsmanagement-in-western-europe.html.

[8]. Is Africa ready for 5G? /Africa/DW/29.11.2019 retrieved from: https://www.dw.com-is-africa-readyfor-5g/9-51474261. 
[9]. Moskowitz, J. M. (2019). We have no reason to believe $5 \mathrm{G}$ is safe.

https://blogs.scientificamerican.comblogs.scientifica merican.com/observations/we-have-no-reason-tobelieve-5g-is-safe/.

[10]. Dilsha, M.D; Neenu, W., 2015, Introduction to 5G Wireless Technology. International Journal of Engineering Research \& Technology (IJERT) NSDMCC, 4 (6), https: www.ijert.org.

[11]. Namibia to assess environmental impact of 5G-developing telecoms retrieved form https://www.developingtelecoms.com and from https://developingtelecoms.com/telecom-

business/telecom-regulation/9841-namibia-toassess-environmental-impact-of-5g.html.

[12]. Rashid, Y., Rashid, A., Warraich, M.A., Sabir, S.S, Waseem, A., 2019, Case Study Method: A
Step-by-Step Guide for Business Researchers, Vol.18

Journals.sagepub.com/doi/full/10.1177/1609406919 862424.

[13]. Baskarada, S. (2014). Qualitative case study guidelines: The Qualitative Report, 19, 1-25. https://www.semanticscholar.org.

[14]. Tellis, W. (1997). Introduction to Case Study. The Qualitative Report, Volume 3, Number 2, July. http://www.nova.edu/ssss/QR/QR3-2/tellis1.html.

[15]. Zainal, Z., 2007, Case Study as a research method. Journal Kemanuslaan bil.9 Psyking.net/htmlobj-

3837/case_study_as_a_research_method.pdf 